Meta

Journal des tradlucteurs

Translators' Journal

\title{
Patterns of Thought in English Translation
}

\section{Blake T. Hanna}

Volume 14, numéro 3, septembre 1969

URI : https://id.erudit.org/iderudit/003014ar

DOI : https://doi.org/10.7202/003014ar

Aller au sommaire du numéro

Éditeur(s)

Les Presses de l'Université de Montréal

ISSN

0026-0452 (imprimé)

1492-1421 (numérique)

Découvrir la revue

Citer cet article

Hanna, B. T. (1969). Patterns of Thought in English Translation. Meta, 14(3),

141-153. https://doi.org/10.7202/003014ar d'utilisation que vous pouvez consulter en ligne.

https://apropos.erudit.org/fr/usagers/politique-dutilisation/ 


\section{PATTERNS OF THOUGHT IN ENGLISH TRANSLATION}

No one who is in daily contact with French and English can fail to notice certain fundamental differences between the two languages. These differences stem, of course, from the fact that the French-speaking person does not think in the same manner as the English-speaking person. His mind works along different lines and the result becomes apparent in the language in which he envelops his thoughts. Unfortunately, these differences are subtle and not easily apparent to the nonprofessional. Consider, for example, the tendency of the French mind toward the abstract or the general. The French-speaking person tends to situate what he has to say on as general a plane as possible, in order to cover all the possible contingencies, or to present it in the abstract, in order not to muddy the waters by identifying it too closely with some specific or concrete case.

The counter tendency, of course, is to situate what one has to say on the concrete, specific level, as close to the real-life occurrence as possible. This latter tendency is more characteristic of English, or for that matter, of any Germanic language, which explains no doubt why it was first pointed out by Alfred Malblanc in his book entitled: Pour une stylistique comparée du français et de l'allemand ${ }^{1}$. Malblanc perceived the fact that the French and the Germanic minds tended to think on two different planes, which he referred to as le plan de l'entendement and le plan du réel ${ }^{2}$.

This obliges the translator to think on two planes as well. The technique might be likened to driving a sports car through the Alps: you have to keep shifting the gears. Let us consider a few examples that will illustrate this.

In some promotional material I came across, we find a well-known automobile manufacturer speaking of the solution 22 portes $»$. This is translated into English as a 2-door layout. Now solution is a mathematical term, while layout is borrowed from the field of design or engineering. This would seem to indicate that what

1. Paris, Didier, 1944.

2. Alfred Malblanc, Stylistique comparée du français et de l'allemand, Paris, Didier, 1963, p. $345,347$. 
the French considered as a problem in mathematics, the English saw as a problem of engineering, which is one of the practical applications of mathematics.

The same principle applies in the translation of a phrase taken from a treatise on social questions which speaks of ...responsabilité, donc de la liberté collective. The English translation renders this as ... responsibility that results in collective freedom. Donc, like solution, is a term borrowed from the field of mathematics, but in English it seems out of place in a treatise on sociology. Mathematical terms, of course, are highly abstract. They belong to a field that has a language in its own right, like French or English, but a language that is far more abstract than either of the latter.

Or consider a short story in which one of the characters ran into a trifling problem in home maintenance. We read: Il essaya de réparer la vitre brisée; il ne parvint qu'à la détruire davantage. The translation of this sentence reads as follows: ...he only succeeded in shattering it further. The word détruire is translated by shattering in this case because English-speaking people don't go around destroying windows, they break them. The term destroy is far too comprehensive and far too abstract. From the English viewpoint, it is better suited to abstractions such as destroying someone's confidence or to national cataclysms, such as: Half of the city was destroyed by the earthquake. When it comes to smashing windows, the English mind prefers something more specific. In the case we are considering, an onomatopoeia was chosen. This is a figure of speech which comes as close to the specific occurrence as possible by giving an auditory impression of what happened.

The same principle held true when the householder went about repairing the damage. Il la remplaça par une feuille de papier qui résonnait sans cesse, which sheet of paper, we are told, gave out a perpetual throbbing sound. Throbbing, of course, is one of the onomatopoetic terms that might appear in a list headed by the generic term resound or résonner.

And while we are on the subject, why did the homeowner repair the broken window in the first place? Because it laissait pénétrer le vent, which comes out in English as let the wind blow in. Thus the English translator specifies, not only that the wind penetrated the room, but how: by blowing. The point is that anybody or anything can penetrate a room: the wind, a noise, the sun, or even the man who came to repair the television set; but only the wind can do it by blowing. This makes the translation more specific than the original, which is exactly the way the mind of an English-speaking person works.

This principle is borne out on nearly every occasion where the two languages come into contact. Millions of little boys, both English and French, have read the novels of Dumas père, bristling as they are with such declarations as: $J e$ vous ai fait apprendre à manier l'épée! In English, this comes out as: ... to handle a sword, rather than to handle the sword, as it says in French. This is because the sword in English means "swords in general », just as we say: «The dog is man's best friend». The English prefers a more specific rendition of this idea 
and thus uses a sword, which means precisely « any particular sword that comes to hand ».

By the same token, the expression sécurite contre le vol in an automobile advertisement was rendered in English as a thief-proof system, the introduction of the word system representing the usual English tendency to specify exactly what it was that resulted in the sécurité spoken of in French. In the same advertisement, précautions become safety features, the word features being a characteristic attempt to particularise the abstract term précautions.

In another text, the French speaks of a plaine surchauffée par un soleil de moisson, which the English translator renders as a plain baked by the harvest sun. Baked, of course, is a specific application of chauffeee, while surchauffée is only a matter of degree. And at the other end of the temperature scale, we find a character appearing in a celebrated Canadian novel who remarks: Le lac est encore bon, meaning you can still walk on the ice. In the English version, this is translated as: The lake is solid yet. It is interesting to note how much more specific solid is than bon, when we are talking about whether the ice is frozen or not.

In general therefore, the English mind tends to hew close to the line of reality, expressing itself in concrete, specific terms, while the French mind thinks in terms of abstract generalities, instinctively reducing things to generic terms that will tend to cover any specific instance of whatever it is that is being discussed. Now, can we consider this as a hard, fast rule that must only be learned by heart to produce infallibly impeccable transiations? Hardly, for here is a case where exactly the reverse occurs. In an engineering text, we find the expression un tourbillon d'air rendered into English as air turbulence, an expression that is far more abstract and generalized than the French original. Such cases are in the minority it would appear, but even if they are, who is going to unravel such problems, so intimately connected with the unconscious thought-patterns of two different cultures? Let me submit that it is a job for the professional translator and in particular, for the professional translator who is working into his native language. I seriously doubt whether anyone else can be counted upon not to go astray.

Another manner in which the respective workings of the French and English minds are revealed is through specification, as opposed to implication. Generally speaking, whatever a person says has meaning behind it. Sometimes however, we come right out and specify what we mean, while at other times, we only imply it. Now French and English handle these two situations differently. Perhaps a few examples will clarify what I mean.

Under certain circumstances, the French uses the term susdit to refer to something that has already been mentioned. In one text I consulted, I found the term used in a sentence that began with the words: Le susdit premier lundi du mois de... This was translated into English by: The said first monday of the month of... Now in this case, the French is more explicit than the English because it tells where the date was mentioned, while the English leaves this detail untold. 
It can well afford to do so moreover, since the fact is implicit in the translation said. If it was said, it had to be said before, and hence printed above, as the expression susdit specifies.

On the other hand, in a form put out by the Health Department, we find une typhoïde referred to, and this expression is rendered in English by a typhoid infection. In this case, the idea of infection is implicit in French and explicit in English, which is just the reverse of the situation described above.

We are therefore confronted with two opposite tendencies, for either language can specify or imply as the occasion demands. The choice of when to do so, furthermore, is not an easy one. You cannot, for example, say a typhoid in English, but you can just as easily say abovementioned or aforesaid in English as you can say susdit in French. This is further borne out if we consider the sign MEN AT wORK. If this is rendered by TRAVAUX in French, the French is implying what the English specifies, namely, that men are doing the work. But on the other hand, if a sign is erected in French reading TRAVAUX DE voIRIE, it specifies something that the English sign merely implies by placing the sign where it is: alongside a road. This tendency toward implication is carried to an extreme alongside a road I know of to the north of Montreal. Two signs have been erected at intervals shortly before you reach the scene of the repair work that is being carried out. Neither of these signs has anything on it but a picture of a pile of earth, but on the second sign, the pile is smaller than it was on the first one.

A further example of specification in English is to be found in the phrase I quoted above: ...responsabilité, donc de la liberté collective/...responsibility that results in collective freedom. I have already dealt with the translator's motivation in getting rid of the word donc. What he put in its place, however, is a case of the sort of specification we are discussing here, for the words that results in specify what was only implied in French by the word donc. The reverse, however, is the case with another example where the expression vers le haut de la pyramide was translated into English in a text I found by at the top. Here, the translator did not feel that the circumstances called for him to specify what it was we were at the top of in the manner in which the French specified it.

Many of these specifications correspond to implications in the source language that are extremely obscure. Take the case of an article on immunology containing the phrase dans les vaccinations récentes. Obviously, since the word récentes is used, we are talking about a vaccination that has already taken place, rather than one which is contemplated. Now, the word dans merely implies this, whereas the English translation after specifies it. The following implication is perhaps even more obscure. We read in a market survey that des relevés à $X, Y$ et $Z$ montrent qu'il y a plus de postes de radio (de telle marque)... The English translator dispatched this statistic with celerity by stating flatly that more people own So-and-so's radios in $X, Y$ and $Z \ldots$ At first glance, it appears that something has been left out. At second glance however, it becomes apparent that what was left out was nonetheless implied by the original. After all, how could they tell whether more people owned So-and-so's radios unless some sort of survey had been conducted? 
A similar example of specification in French is to be found in the expression d'un seul trait de plume. The English translator of one text I read translated this by at $a$ dash, implying through the context what made the dash, whereas the French had specified that it was a pen. Another example is: Quand vous aurez la réponse, vous me le direz, which was translated in one case by: When you get the answer, let me know. Here, the words quand and when situate the action in the future. This being the case, the French specifies futurity in the tense of the two verbs, while the English does not, since the word when implies it.

On the other hand, here are two examples of the reverse: In a French novel I read, I found the expression ...dont la couleur s'était transformée. In the English translation, this appears as ...the colour of which had faded. The context makes it highly unlikely that the colour got darker. Transformée, however, only implies that it got lighter, while faded specifies. Or again, another text I found contained the words: Il resta immobile, which were translated into English by: He stood there motionless. Of course, if he stood anywhere, it had to be there. The English specifies this, while the French does not, since the fact is implicit in the rest of the phrase. By the same token, the English specifies what the man was doing by using the verb stood. The French original contented itself with implying this through the verb resta, since the context would hardly have led anyone to suppose, for example, that the man was hanging by the neck.

Now, where do we stand on the question of specification? The above examples contain about twice as many cases where the English specifies as they do where French specifies. This would apparently reveal English as being twice as apt to specify as French. On the other hand, the sampling is hardly representative and if several hundred or several thousand such cases were analyzed, a different ratio might emerge. One thing that does seem certain however is that a great deal more study ought to be devoted to this question. And for the moment, we are obliged to conclude that matters such as these are related to the most subtle thought-patterns of two different cultures. Thus, when a passage from one language is to be translated into another, it had best be left to a professional working into his native language to decide whether to imply or to specify. For my own part, I doubt very much that I would go far wrong if $I$ chose to specify or to imply in a translation into English, but I cannot say as much if I were required to work into French.

One of the most revealing ways in which to get at the thought-patterns of a culture is to observe the way its members speak. The basic function of language, of course, is communication, but in communicating, the speaker invariably furnishes the listener with a good deal of information about himself, as well as about his subject. This is why translators are so good at dealing with such matters. They are professionals who are trained precisely to observe how the members of two different cultures speak. In doing so, moreover, they are descending from the level of thought-patterns alone to the level of the message itself, in the hope of finding in that message additional information concerning the thought-patterns.

An excellent example of the way the message betrays the thought-pattern 
behind it is to be found in the little cars people like to ride in amusement parks. They run on hidden wheels around a rink and they take their current from a metal ceiling overhead. Such contrivances are to be found everywhere: at Coney Island in New York, on Île Ronde in Montreal, and in the Place de la Bastille in Paris. Everywhere, they are exactly the same, so it cannot be maintained that the object being described in the two languages is in any way different. However, in French, they are known as autos-tamponneuses, while the English refer to them as dodg'ems. The choice of terms speaks volumes about the people who use them. I have watched them being used in fact on both sides of the Atlantic, and the only thing I have ever seen anyone do with them was to run into other little cars of the same sort. And yet the French use a term that realistically announces their intention to behave in this manner, while the English expression, which comes from a verb meaning to avoid, announces an intention to do the opposite. The same may be said of the person who directs a meeting or a discussion. The French call him an animateur, while the English call him a moderator. Both of these examples illustrate a procedure called «modulation» which is resorted to on numerous occasions by the professional translator. It consists of presenting the same reality as that presented by the source language, but viewing it from a different angle. It is justified by the fact that the cultures speaking the two languages involved really do view certain realities from different angles, as we have just seen. In the cases cited above in fact, the reality involved is viewed from diametrically opposed angles by the two languages involved.

In other cases however, the reality is simply viewed from a different angle, not necessarily one diametrically opposed. Take for example a case I picked up in a magazine article where a professional school was referred to metaphorically as une pépinière. The English translator substituted another metaphor, borrowed from the vocabulary of athletics, rather than from that of gardening. He called it a training ground. In a similar case taken from another text, we are asked the question in French: N'en est-il qu'aux balbutiements? where the balbutiements represent metaphorically the initial stages of an enterprise. In English, this becomes: Is he still only groping his way along? The metaphor introduced here depicts infancy, but the change wrought by the English translator gives a visual impression of it, rather than the auditory impression given by the French original.

In many cases, the change of viewpoint introduced by a translator who resorts to this type of modulation may be described with a good deal of precision. Consider, for example, a phrase taken from a well-known Canadian novel: La nouvelle sombra dans l'indifference. In the English version, the translator put: The item was received without interest. This is a particular example of modulation wherein the translator uses the contrary of the original, but puts it into the negative. Interest, of course, is the antonym of indifference. The translator was thus obliged to put the word into the negative in order to preserve the meaning. He would have done even better if he had thought of some way of preserving the beauty of the metaphorical term sombra. As it is, he stands convicted of having sacrified grace on the altar of semantics.

I mentioned earlier: The dog is man's best friend and quoted a passage 
concerning the handling of a sword. These were cases of a figure of rhetoric known as synecdoche, which means taking the part for the whole or the whole for a part. It is not unusual to hear it used, even in every-day conversation. I have often heard people around me refer to fire engines as « reels» or call bicycles «wheels». In some places, cars are referred to as «motors». These are cases where the whole is called by the name of one of its parts. In English, vin de Champagne is known as Champagne, which is an example of the opposite: calling the part by the name of the whole. In this case, a product is referred to by the name of the region that produces it. The same thing happens when someone says: "That's a splendid Rembrandt you have on the wall 》, or when people say: "They called in the law $»$, meaning somebody called the police.

Synecdoche is frequently resorted to by professional translators, who value the possibilities it offers for modulation. Consider, for example, the expression l'homme libre, which I found translated in one article as free men. In another case, the expression de ses premiers pas was translated by from earliest infancy. In a description of a scene from the early days of radio, the French original spoke in one case of modestes galènes and the translator rendered it by modest crystal sets. This recalls the early period of radio broadcasting when the galena crystal was used as a detector in radio sets. All of the foregoing are examples of cases of synecdoche where the whole is used for the part or the part is substituted for the whole. A more recent example than the one involving crystal radios turned up in a text put out by the telephone company, which spoke of diminuer le travail des téléphonistes. The English translation pointed out that this reduces switchboard work.

Another relationship that is frequently exploited by translators resorting to modulations is the cause-effect relationship. Here, the effect produced is substituted in the translation for whatever caused it, appearing in the original. The reverse can also be used. In an earlier paragraph, I mentioned a translation where sécurité contre le vol was rendered by a thief-proof system. Here, the effect is in the source language and the cause is in the target language. The opposite is true of a phrase describing the ice going out in the Spring, where the remark: La glace s'est fendue... is translated by: The ice went... In this case, the character in the story mentions the cause in French, while in the English translation, he is made to allude to the result. A similar case is to be found in an article on research which asks the question: Les recherches fondamentales ont-elles été suffisamment poussées? In the translation, the word poussées is translated by advanced. Now, if this research is advanced, it is because somebody got behind it and pushed; thus, the cause is in the original and the effect is in the translation.

A further example of the interchange of cause and effect in translation is furnished by an article on economics which states: Des crédits considérables sont mobilisés par des organismes publics et privés... In the English translation, this statement begins with the words: Large sums of money are being spent... It is interesting to note the fundamental difference in thought-pattern represented by the original and its translation. The French original uses the word crédit, which the dictionary defines as a somme prévue par le budget or the possibilité d'obtenir 
des capitaux. You must, of course, have money at your disposal on the credit side of the ledger before you can undertake to spend it, the expenditure being entered on the debit side of the ledger. Crédit therefore represents the cause in a cause-effect relationship where the sums ... spent in the translation are the result.

The inverse process is represented by another example where we find the phrase: Il a fallu que... de grands hommes sinclinassent sur..., which is translated into English by: Great men have had to toil over... The reason why they were bending over was that they were toiling, or working hard. This time therefore, the cause is in the translation and the effect is in the original. Another curious example of the same pattern is to be found in an automobile advertisement where we read that la largeur intérieure a été calculée pour donner le maximum d'aisance. The English translator could have rendered this by the maximum in comfort, but he chose not to. Instead, he translated it by the maximum seating capacity. This is rather an odd thing until you think about it for a minute. Then you realize that he simply reasoned that if anything had been done to the largeur interieure that would result in aisance, it must have been an increase in seating capacity. Or in other words, he simply got rid of the effect and substituted the cause. The reason why he did this, by the way, is an example of something I spoke of in the opening paragraphs of this article: the plane of abstraction, as opposed to the plane of reality. Aisance is an abstraction situated, as Malblanc would say, sur le plan de l'entendement. Seating capacity, on the other hand, is something specific, situated on the level of reality. Now, I wonder whether the translator stopped to think all this out. Frankly, I doubt it, for the type of modulation I am dealing with here follows a thought-pattern that is largely subconscious. This is why, to a very large extent, people who translate into a language other than their native tongue are treading on thin ice, and why up until now, nobody has succeeded in substituting a computer for a translator. But let us return to this point later.

Numerous other modulations betray a difference in thought-pattern between the speakers of the two languages involved. A change from the active to the passive voice, or vice versa, is a case in point. We might consider a phrase I picked up in a random magazine article as an example of this. It read: On serait tenté de dire..., and the translator rendered it by the phrase: It could even be said..., substituting the passive voice for the active. The message remains exactly the same, even to the nuance of doubt rendered by serait/could and the shade of hesitation betrayed by the presence of the verb tenter, which the translator respected by using the adverb even. Obviously, given the choice between this translation and one would be tempted to say, he chose the preferable rendition, for reasons that are immediately apparent to any English-speaking person, but which any Englishspeaking person would be hard-pressed to explain. One sounds stilted and we have a tendency to put things in the passive voice anyway. Perhaps it is simply because we think that way, a verity that the French, with their penchant for generalization try to sum up by referring to le génie de la langue.

It cannot be denied that the English-speaking mind does run to passive voices. In a published analysis of the characteristics of a foreign car I read recently, for example, the writer pointed out: Elle pousse sa seconde vitesse aussi loin qu'elle 
le désire. The English translator took this remark all to pieces and put it back together again in the passive voice, as follows: The second speed can be maintained as long as desired.

Space does not permit me to examine all the cases in which the message is treated in a translation in such a way as to reveal something interesting about the thought-patterns of the people using the two languages. To mention but a few cases, note that the concepts of time and place do not coincide in the two languages. The French frequently uses an expression denoting place, where the English would use a term expressing time. This is reflected in such translations as: Là où (telle ou telle chose se produit)/Whenever (such and such happens); or: Dans tous les cas où /Every time...

I found another interesting passage where the translation betrayed a difference in thought-pattern in the house-organ of a large North American corporation, where the phrase un minimum de $200 \ldots$ was translated by 200 or more... Apparently the English translator considered minimum in this case as being a rather negative way of putting it, since it underlined the smallness of the number 200 under the given circumstances. He therefore preferred a more positive approach and translated it by or more, which says the same thing, but which puts the accent on the fact that 200 is only a starting-point and that better things are to come. Here again, the translator probably did not sit down and think all this out. But his thought-patterns obviously ran in channels that are particularly characteristic of the English turn of mind.

In yet another case, an adaptation this time, the translator used once you get started, you can hardly stop in a cake-mix advertisement as a translation for l'appétit vient en mangeant. Obviously, the message conveyed by the French text was far richer in connotations than any English equivalent he was able to think of. The adaptation finally settled upon renders the drift of the original, but does little more. The translator's task in this case was all the more delicate in that the text in question appears in letters two inches high under a full-page advertisement of a cake in living colour. On the other hand, it was facilitated in that he had the picture of the cake to help him. The weakness of the solution settled upon is illustrated by the fact that the French original can stand alone, while the English translation needs the cake to make any sense. The difficulty, of course, is that the French have thought deeply about matters of cuisine, while the English have not. This leaves the French with a host of agreeable mental associations that the English translator cannot fall back upon. It would have been closer to the mark to have translated by: The more you eat, the more you want, but this is an equivalent that treads far more heavily than the discreet French original. It suggests at the least making a pig of yourself by eating too much cake, which is hardly a train of thought the manufacturer wanted the reader to embark upon.

Culinary matters are a field in which the French have a broad spectrum of thought-patterns which the English do not have. We must therefore expect to find a gap in the English on the level of the message, when it comes to culinary matters. 
This gap is indeed reflected on the lexical level by a variety of loan words, such as cuisine, à la mode, petits fours, etc.

Similar gaps turn up from time to time in other places. Both languages for example use similar metaphors when dealing with someone who has gained promotion by staying with the same company: Sorti des rangs/Came up through the ranks. This is not true, however, under the opposite circumstances, where a high-ranking executive is hired away from another company. French uses a metaphorical term for this: parachuter or parachutage, while the English must content itself with the term I just used, hired away from, or else say he was brought in from the outside. It is, of course, worthy of note, when two languages use the same metaphor, to describe a given situation, but when one of them can find no metaphor at all, to describe the opposite situation. It must be admitted, however, that the gap in thought-pattern in this case is difficult to explain.

In the previous paragraph, I mentioned the metaphor used for a man promoted within his own company. The image itself is borrowed from the military vocabulary in the case of both languages: Sorti des rangs/Came up through the ranks. It is interesting to note, however, that there is a difference of aspect in the manner in which this image is manipulated in the two languages. In French, it is sorti. This seizes the action upon its completion, whereas the English says came up through, depicting the action as it unfolds. This is a question to which J.-P. Vinay and J. Darbelnet have devoted considerable attention in their Stylistique comparée $d u$ français et de l'anglais ${ }^{3}$. Sorti is a case of perfective aspect and came up through, of durative aspect. Numerous examples of differences in aspect are to be noted between translations of an equivalent message and each one betrays a subtle difference in thought-pattern that concerns, not the concept being thought about, but the manner in which it is thought out. Consider, for example, the following phrase, picked out of a philosophical treatise: Alors que craquent les principes millénaires... It was translated into English by: While age-old concepts are crumbling... Apart from the onomatopoeias involved, craquent is what MM. Vinay and Darbelnet would call inchoate aspect, since it marks the beginning of the action, while crumbling is durative aspect, since it depicts the process as it unfolds.

A passage mentioned earlier, taken from a public-health bulletin: Dans les vaccinations récentes/After recent vaccinations, bears witness to a similar change in aspect. Dans endows the action of vaccination with punctual aspect, since it situates us at a point in time whose dimensions cannot be measured. After, on the other hand, situates us at a time when the action of vaccination is completed. This is known as perfective aspect.

Sometimes when the translator sees fit to specify a point that the original only implies, what he is actually specifying is the aspect. An example of this is the passage ...rivalités qui se révèlent inutiles, which I discovered in an article on economics. It was translated by ...competition that so often proves useless. The words so often add an iterative aspect to the action of proving useless. They put it into a sort of frequentative form to stress that the action occurred over and over

3. Jean-Paul Vinay et Jean Darbelnet, Stylistique comparée du français et de l'anglais, Paris, Didier, 1958, p. 75-86. 
again. Apparently the translator felt that the French original implied this. $\mathrm{He}$ appears to be correct, for if you take the words out, you have ...competition that proves useless, a translation that somehow does not quite say all that the original implied.

Similar indices of divergent thought-patterns are to be found in the vectorial indications with which the message is frequently sown in both languages. These are like little arrows strewn about the text and whenever they run in counter directions, translation will bring the fact out. We have already seen that animateur and moderator are polarized in opposite directions. The same thing is true of decisions, which are prises in French, but made in English. Prises seems to indicate that the French mind conceives of decisions as a choice among several options, one of which must be selected. Made, however, seems to betray a more aggressive view of decisions, suggesting that the English mind feels it has created something when it has made one, in all likelihood, a plan of action. The interesting thing is that when the expression is used in the passive voice and in connection with matters other than business administration, it is not unusual to hear taken used instead of made, thus: The decisions taken by the Ministry of Foreign Affairs in this case were... I believe that this betrays a different state of mind from that of the aggressive, decision-making businessman. It probably underlines the arbitrary and somewhat empirical side of decision-making, or of decision-taking.

If we turn from the message itself to the words in which it is expressed and the manner in which they are put together, we find the same subtle traces of a different thought-pattern that is brought clearly into focus in translation. In an article on chemistry, for example, I read: Dans les universités, on s'efforce de résoudre, par des techniques de plus en plus complexes, des problèmes posés à l'échelle subcellulaire et moléculaire. This is translated by: Universities are striving to solve problems on the molecular and subcellular levels by increasingly complex techniques. Fundamentally, this sentence tells us who did something, what was done, and how. But the two languages present these three pieces of information in a different order. First of all, they take a different view of who did it. The French does not feel right about saying the universities did it, because, from the French standpoint, the universities were where the thing was done. Hence, the French puts this piece of information in the form of an adverbial phrase. This leaves the sentence without a subject, and since the latter is not clearly identified in any case, the French uses on. The English, on the other hand, resorts to synecdoche, taking the whole (the universities) for one of its parts (the people working there). This solution is particularly agreeable to the English mind, since it kills two birds with one stone.

Next, the French sets about telling how the thing was done, in order to save the best part - what was done - for the last. This is known as climactic word order and it has the advantage of sustaining reader interest. The English, however, will have none of it, as it feels the direct object should come immediately after the verb. It does not seem reasonable to the English mind to discuss how a thing was done before telling what it was that was done. Hence, the English reverses the order of the last two elements of the sentence. 
Another example of climactic word order in French that the English felt constrained to reorganize is to be found in this passage: Apprentissage difficile dont personne ne peut garantir la réussite. Here, the English sees a relationship of cause and effect between the apprentissage difficile and its subsequent réussite, and it is annoyed to find the French interrupting this train of thought to launch into what appears to be a side issue involving personne and garantir. Hence in translating, the sentence is reassembled in such a manner as to eliminate the interruption and bring together what to the English mind appears related: $A$ difficult apprenticeship whose successful outcome no one can guarantee.

What conclusions can we draw from the foregoing considerations? First of all, let me point out that the examples $I$ have used are drawn from the published work of countless professional translators, as found in folders, advertisements, instruction sheets, magazines, books and forms used in various governmental agencies; in short, from the type of material the professional translator is called upon to produce each day. Insofar as possible, I have attempted to limit my documentation to translations into English of material first published in French, either on this side of the Atlantic or in Europe.

It would, of course, be foolish to attempt to draw statistical conclusions from the examples cited. A far broader spectrum of cases would have to be studied before this could be attempted, dealing with every facet of translation where the thought-patterns of English or French may be shown to diverge or to coincide. And yet the examples used do show a considerable divergence between the thought-patterns of the two languages, even if they do not allow us to define their nature. What they do reveal is the necessity to devote further study to an attempt to evaluate the rôle of thought-patterns in the field of translation. This has not yet been done. A great deal of attention has indeed been devoted to the indissolubility of a given concept and its linguistic manifestation, particularly by linguists of the Saussurian school, but much remains to be said about the different thought-patterns that make the linguistic manifestation of a given concept different from one language to another.

This is perhaps easiest to grasp if we illustrate with an example drawn from the field of mathematics. Where the French uses the expression neuf sur dix to express a certain concept, the English uses the expression nine out of ten. Now in this particular case, the concept in question may be isolated from its linguistic envelope, since we have at our disposal another more abstract language in which to express it. This is the language of mathematics and it expresses the concept as 9:10. Now the difference between $9: 10$ and neuf sur dix must represent the applicable thought-pattern in French, just as the difference between 9:10 and nine out of ten must represent the corresponding thought-pattern in English.

If we could apply this method to everything we have to deal with, we could probably identify all of the thought-patterns of a given language. Unfortunately, we do not have such systems of notation as 9:10 in every case to help us isolate the concept from its accompanying linguistic envelope. Hence we are reduced to comparing the linguistic envelopes themselves: neuf sur dix vs. nine out of ten. It would seem therefore that the thought-patterns of a language are a third dimension 
that must be added to the bidimensional Saussurian sign if we are to get at the root of the matter.

This obliges us to answer an important question: Can the thought-patterns of one language really be deduced by comparing its linguistic patterns with those of another language? What this amounts to is defining one language in terms of another. Or to put it another way, is the study of comparative stylistics a valid approach, or must we isolate the concepts involved instead, as we did with 9:10? Personally, I see no alternative for the moment to the study of comparative or multilateral stylistics in the expectation that the linguistic patterns of one language will cancel out the patterns of another, exposing the thought-patterns involved.

This is where the translator comes in, for translators must come to grips each day, not only with concepts and their linguistic manifestations in two languages, but also with the differences in thought-patterns that make the linguistic envelope different from one language to another. This is no easy task, as any professional translator will agree, for it imposes upon him the constant obligation of shifting from one thought-pattern to another, a technique I have already compared with driving a sports car through the Alps.

To be more specific, he must impose upon himself passively the thoughtpattern of the source language and he must follow actively and creatively the thought-patterns of the target language. This is why it is better to have a translator work into his native tongue. He is less apt to go astray in the thought-patterns he follows. This is also the reason why we cannot as yet entrust translation to a computer. Computers can only do what they are programmed to do. At present, we can program them, at least to a limited extent, with concepts and the linguistic envelopes to put them in. We still have no idea how to program them to follow the thought-patterns of a given language because we do not understand these thought-patterns ourselves. We are, on the other hand, relatively safe with an experienced translator working into his native language, because he comes already programmed with a full set of the right thought-patterns.

In conclusion therefore, let me say that much remains to be done in our study of the thought-patterns of English as they affect translation, but that we already know enough about them to state that such translation is unquestionably a task that requires the services of a professional, and preferably one who can work into his native language. And as to the research that remains to be done on thought-patterns themselves, I believe it should be pushed resolutely ahead. No one is better placed to isolate and study the thought-patterns of a linguistic group than the professional who must deal with them in the pursuit of his daily bread.

BLAKE T. HANNA 